\title{
Design, Fabrication and Testing of Gravity-Powered Light
}

\author{
Sushant Raj Giri, Prashant Lakhemaru, Anil Shrestha, Sanjeev Lama, Shuveksha Sapkota \\ Department of Industrial Engineering, Thapathali Campus, Institute of Engineering, TU, Nepal \\ Corresponding author: lakhemarup@gmail.com
}

Received: Nov 1, 2018

Revised: $\operatorname{Dec} 23,2018$

Accepted: Dec 25, 2018

\begin{abstract}
With every passing day, the need for sustainable living on Earth is increasing greatly. For this world needs to start using renewable energy resources. The following project shows how electricity can be generated using gravity in simplest possible way. Mechanical components like Spur gears, chain and mass provide input to an electrical circuit through a generator motor. Every time you lift the weight, gravitational potential energy is converted into electrical energy for 12 seconds in this model. The power generation from gravity is cheaper and bio-efficient as compared to solar and other renewable energy sources. In recent times due to effects of pollution and global warming there is a need for generating power from renewable sources. The reason for generating power using gravity is that it is available all over the Earth, abundant and consistent too. In this project, the gravitational energy of a heavy particle is converted to the electrical energy. When the heavy particle falls down from a higher altitude to a lower one, its potential energy is converted into the kinetic energy. Then this energy is converted to electricity by using a synchronous motor. With the increasing of the altitude of the load, the lighting time increases. If load increases, power production also increases, but the lighting time decreases.
\end{abstract}

Keywords: Gravity light, fabrication, payback

\section{Introduction}

Gravity, or gravitation, is a natural phenomenon by which all things with mass are brought toward (or gravitate toward) one another, including planets, stars and galaxies. Since energy and mass are equivalent, all forms of energy, including light, also cause gravitation and are under the influence of it. On Earth, gravity gives weight to physical objects and causes the ocean tides. The gravitational attraction of the original gaseous matter present in the Universe caused it to begin coalescing, forming stars and the stars to group together into galaxies, so gravity is responsible for many of the large scale structures in the Universe. Gravity has an infinite range, although its effects become increasingly weaker on farther objects [4]. The gravity light concept was founded in 1992, and in the 21 years since, the growth and success patterns have far outgrown industry standards [2]. Sir Isaac Newton had discovered the phenomenon of gravity near 400 years ago. London researches Martin Riddiford and Jim Reeves who have spent four years for developing gravity light as an off line project and have worked on an inexpensive and safe alternative that will be of great benefit to many people across the globe - a gravity-powered LED light. They are using tried and tested manufacture who has the right knowledge to make gravity light [3]. 
Global Scenario: Gravity light is a revolutionary new approach to storing energy and creating illumination [1]. Chun-chao Wang and Yuh-suiang Wang have successfully invented the concept of gravity power generation mechanism. Unlike solar-powered lamps, the gravity light can be operated all the day and night and under any climatic conditions with zero running costs. Gravity light is a light solution that generate light by just pulling certain weight for certain time to generate light for 30 minutes .It is a device that produces a light source, or power, using gravity and comes without battery, solar panels or any other form of energy producing or storing capabilities. Since it does not require a battery, it is not only environmentally friendly, but also less prone to require regular replacements as batteries deteriorate over time. The primary objective of his invention is to provide gravity power generation mechanism which can provide a continuous and stable operation to continuously convert the gravity potential energy into the kinetic energy and then to convert the kinetic energy into electrical energy, so as to perform a long time, effective and stable energy output. Russian Inventor Mikhail Dmitriev to know about his gravity motor has apparently devised a mechanism whereby static gravitational pull can be harness to generate useful energy. He has worked for many years developing and testing gravity powered devices and he has been very successful in his work. His various designs is based on the principle of having weights attached to a wheel and arranging for those weights to be offset outwards when falling and offset inwards when rising. Because of the different lever arms involved, that gives a force imbalance which causes the wheel to rotate continuously and if the weights are of a considerable size, then the rotation is powerful and can be used to generate electrical energy.

Local Scenario: Locally, in small scale it can be used at areas which have no facilities for electricity. The device consists of a body that includes the lamp and the power generation unit, and a weight that is used to produce the power. From what it can tell, it needs to fill the weight with sand, rocks or any other weights and lift it up for a couple of seconds. Power gets generated automatically from then on until the weight reaches the initial position again which seems to be good for certain time of lighting. It can then be lifted the weight up again to produce additional power and lighting.

Problem Statement: In this global age of technology and science more than $17 \%$ of the world population still lacks electricity. The figures reach much higher numbers when it comes to underdeveloped countries like Nepal. Lighting is one of the basic needs for any household or small scale industries to thrive. The lack of lighting in rural areas along with low supply of electricity causes many people to still live their livelihood in the dark. This hampers growth of the individuals and the overall development of the country. Our country blessed in abundance with natural resources for hydroelectricity cannot sustain energy needs by itself. The financial cost of getting electricity and lighting in every home is a high bargain for our challenging terrain. A cheap and efficient solution for lighting is required in order for the poor to raise their standard of living. The key to success in reaching this goal is affordability and mobility. The proposed solution should be cheap enough for the poor to afford and use. The project put forth by this team tries to battle this issue of providing light to the poor using cheap and readily available materials. The completed project will provide a prototype that can be further developed in order to achieve industrial manufacturing competence.

Significance of study: In recent times due to effects of pollution and global warming there is a need for generating power from renewable sources. The reason for generating power using gravity is that it is available all over the Earth, abundant and consistent too. In this project, the gravitational energy of a heavy particle is converted to the electrical energy. When the heavy particle falls 
down from a higher altitude to a lower one, its potential energy is converted into the kinetic energy. Then this energy is converted to electricity by using a synchronous motor or dynamo. With the increasing of the altitude of the load, the lighting time increases. If load increases, power production also increases, but the lighting time decreases. Using $1 \mathrm{~kg}$ of load from the elevation of $0.6 \mathrm{~m}$, the dynamo output was found to be $0.3024 \mathrm{~J}$ and the lighting time is 12 seconds. However, varied challenges were experienced during the project that is yet to be overcome to convert it to a successful commercial product.

\section{Methodology and Working Principle}

The process of energy conversion begins by lifting a mass of estimated 1-2 kg through a certain height of up to few meters. The weight is fastened or fixed using a holder mounted to a chain drive. This weight acts as the main driver that will help us obtain the necessary gravitational force for energy conversion.

The weight suspended is mounted on a chain drive that is passed through sprockets to obtain rotational energy and provide support for the weight of the mass. The sprocket receives rotational energy from the chain drive as the gravitational force moves the weight in the direction towards the center of the earth. This rotational energy so obtained from the sprocket is then transferred to a gear with a large diameter and high number of teeth. The gear is joined along with the sprocket by method of welding. Hence the rotational motion that is observed by the sprocket is also experienced in the gear.

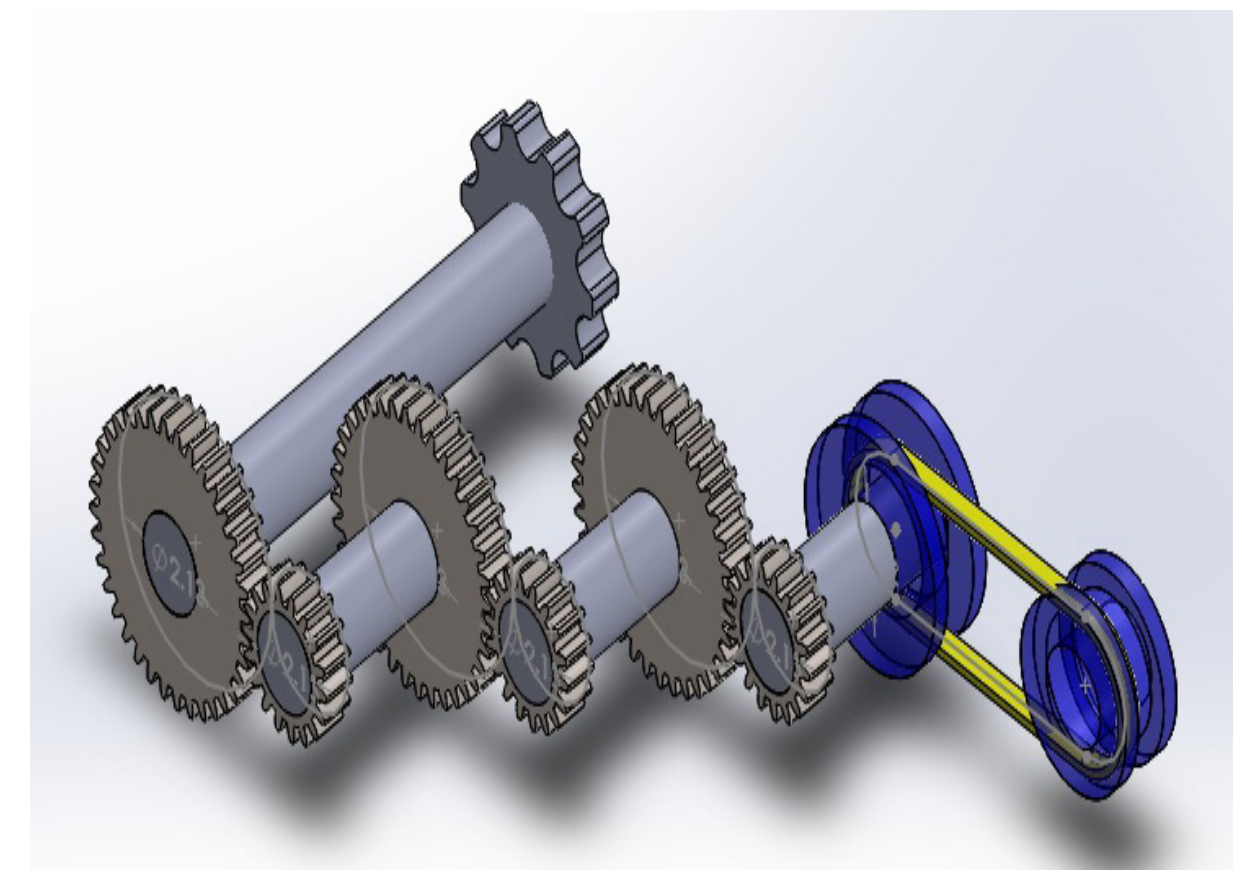

Fig. 1: Schematic representation of Gear Mesh

The gear now has rotational motion and a definite RPM. The RPM is then increased many folds by the use of a gear train. The gear train uses gears of different sizes to change the RPM as required. 
Hence, we can achieve our desired RPM with the correct number and sizes of gears. The final gear on the gear train is used to drive a pulley and a belt drive. The belt drive is used to power the DC generator which is then used to produce the required electricity. This is the final stage of the electricity generation process. This electricity so produced can be used for various purposes but the main focus of our project is for lighting. The DC electricity will then be connected to a LED bulb to convert into light energy. LED light has a very high efficiency and will provide high levels of illumination as our requirement.

\section{Calculation}

\section{Calculation of efficiency}

Using $1.8 \mathrm{~kg}$ of load, the potential energy of the load for an altitude of $0.6 \mathrm{~m}$,

$$
\begin{aligned}
& \text { P.E. }=\text { mass } \times \text { gravity constant } \times \text { height }=1.8 \mathrm{~kg} \times 9.81 \times 0.6 \mathrm{~m}=10.596 \mathrm{~J} \\
& \text { Power }=10.596 / 12=0.883 \mathrm{~W}
\end{aligned}
$$

This potential energy is converted to the electrical energy by the dynamo.

Hence, Dynamo output $=$ Voltage $\times$ Current flow $\times$ time of load landing

$$
=2.1 \mathrm{~V} \times(12 / 1000) * 12=0.3024 \mathrm{~J}(\mathrm{~V}=2.1 \mathrm{~V}, \mathrm{i}=12 \mathrm{~mA}, \mathrm{~T}=12 \mathrm{~s})
$$

Power $=0.3696 / 12=0.0252 \mathrm{~W}$

The height from where the load is falling by the gravity is, $h=0.6 \mathrm{~m}$, time required $(\mathrm{t})=12 \mathrm{~s}$.

Hence, velocity of the falling mass, $v=5 \mathrm{~cm}$ per second.

$$
\text { Eff. }=(\text { Output } / \text { Input Energy }) * 100 \%=(0.3024 / 10.596 \mathrm{~J}) * 100 \%=2.85 \%
$$

\section{Experimental Data}

Table 1: Design Specifications

\begin{tabular}{|c|l|c|l|}
\hline $\begin{array}{r}\text { S. } \\
\text { N. }\end{array}$ & Material & Quantity & \multicolumn{1}{|c|}{ Dimension } \\
\hline 1 & Metal sheets & 2 & $\mathrm{~L}=60 \mathrm{~cm} \mathrm{~b}=4 \mathrm{~cm}$ \\
\hline 2 & Dynamo & 1 & $6 \mathrm{~V} 3 \mathrm{~W}$ \\
\hline 3 & Spur Gears (Large) & 3 & $\mathrm{D}=256,240,240 \mathrm{~mm}$ \\
\hline 4 & Wooden Shaft & 3 & $1=130 \mathrm{~mm} \mathrm{D}=24 \mathrm{~mm}$ \\
\hline 5 & Spur Gears (Small) & 3 & $\mathrm{~N}=36, \mathrm{D}=32 \mathrm{~mm}$ \\
\hline 6 & Ball Bearing & 6 & Diameter $=9 \mathrm{~mm}$ \\
\hline 7 & LED Light & 3 & $6 \mathrm{~V}$ DC diodes \\
\hline 8 & Nuts-Bolts & 4 & Diameter $=9 \mathrm{~mm}$ \\
\hline 9 & Nuts-Bolts & 16 & Diameter $=7 \mathrm{~mm}$ \\
\hline
\end{tabular}

Varied masses were placed on the sprocket by means of chain. The following lighting time and power were found. 
Table 2: Data table of weight, height and time

\begin{tabular}{|c|c|c|c|}
\hline S. N. & WEIGHT $(\mathrm{KG})$ & HEIGHT $(\mathrm{m})$ & TIME $(\mathrm{sec})$ \\
\hline 1 & 1.5 & 0.5 & 16 \\
\hline 2 & 1.8 & 0.6 & 12 \\
\hline 3 & 2 & 0.7 & 13 \\
\hline 4 & 2.2 & 0.7 & 10 \\
\hline 5 & 2.6 & 0.8 & 7 \\
\hline
\end{tabular}

Table 3: Data Table of weight and power

\begin{tabular}{|c|c|c|}
\hline S. N. & WEIGHT $(\mathrm{KG})$ & POWER $(\mathrm{W})$ \\
\hline 1 & 1.5 & 0.459 \\
\hline 2 & 1.8 & 0.8829 \\
\hline 3 & 2 & 1.05 \\
\hline 4 & 2.2 & 1.51 \\
\hline 5 & 2.6 & 2.91 \\
\hline
\end{tabular}

\section{Economic Analysis}

Table 4: Material Cost

\begin{tabular}{|l|l|l|l|l|}
\hline Material & Specifications & Cost/Unit (Est.) & Quantity & Total (Rs.) \\
\hline LED bulbs & 6 V DC & 20 & 5 & 100 \\
\hline Dynamo & 6 V DC 3W & 500 & 1 & 500 \\
\hline Gear (Large) & Spur (256,240,240D) & 3000 & 3 & 9000 \\
\hline Gear (Small) & Spur (32D) & 100 & 8 & 800 \\
\hline Sprocket & & 300 & 1 & 300 \\
\hline Chain & $150 \mathrm{~cm}$ & 300 & 1 & 300 \\
\hline Load & Any & 0 & 1 & 0 \\
\hline Wires & & 50 & 1 & 50 \\
\hline Nuts and Bolts & $9 \mathrm{~mm}$ and 7mm & 15 & 20 & 300 \\
\hline Other Expenses & & & & 1500 \\
\hline \multicolumn{1}{|c|}{ Total } & & & & 12850 \\
\hline
\end{tabular}

Table 5: Overhead Cost

\begin{tabular}{|c|c|}
\hline Process & Cost \\
\hline Cost of Machining & Rs. 2500 \\
\hline Cost of Electricity & Rs. 700 \\
\hline Cost of Labor & Rs. 800 \\
\hline Total & Rs 4000 \\
\hline
\end{tabular}




$$
\begin{aligned}
\text { So, Total Cost } & =\text { Material Cost }+ \text { Overhead Cost } \\
& =12850+4000 \\
& =\text { Rs. } 16850
\end{aligned}
$$

\section{Comparative Analysis of the system with Solar Lighting System}

$$
\begin{array}{lll}
\text { Cost of Solar Electricity Generation (Estimated) } & \\
\begin{array}{lll}
\text { Cost of 25W solar panel } & =\text { Rs. } 3500 & \\
\text { Cost of } 12 \mathrm{~V} \text { battery } & =\text { Rs. } 1500 & \\
\text { Total material cost } & =\text { Rs. } 5000 & \\
\text { Cost per Watt } & =5000 / 25 & =\text { Rs. } 200 \\
\text { Cost per Kilowatt } & =200 / 1000 & =\text { Rs. } 0.2
\end{array}
\end{array}
$$

Cost of Gravity Light Electricity Generation

Total material cost for speed breaker setup $=$ Rs. 12850

$$
\begin{array}{lll}
\text { Cost per watt } & =12850 / 25 & =\text { Rs. } 514 \\
\text { Cost per Kilowatt } & =514 / 1000 & =\text { Rs. } 0.514
\end{array}
$$

\section{Payback Period}

\section{Payback period for solar:}

Assuming that solar hour available is 4.5 hours per day in average.

$$
\begin{array}{cll}
\text { So, in a day unit of power produced } & =25 * 3.6 * 4.5 \mathrm{Kwh} & =405 \mathrm{Kwh} \\
\text { Energy tariff rate } & =\text { Rs } 10 \text { per unit } & \\
\text { Payback period } & =5000 /(405 * 10) & =1.235 \text { days }
\end{array}
$$

\section{Payback period for gravity light:}

Assuming that power can be produced 9 hours in a whole day (in average).

$\begin{array}{lll}\text { So, in a day unit of power produced } & =25 * 3.6 * 9 \mathrm{Kwh} & =810 \mathrm{Kwh} \\ \text { Payback period } & =9300 /(810 * 10) & =1.148 \text { days }\end{array}$

Hence, payback period for power generation using gravity light is less than solar power harnessing.

\section{Conclusion}

Thus we have successfully conducted the project using a mechanical model and can claim that it is feasible to generate electricity with the help of gravity. Further developments can be made in this field to make it more efficient and resourceful. Renewable energies are currently looked at as the sources which will meet the future energy requirements. Solar, Wind, Tidal, Geothermal are some popular examples of renewable energy sources. Yet these sources have their own unique geographical as well as other limitations and are not available throughout. But gravity scale to generate electricity any time at any place. The impact will be beneficial for the social, health and economic situations of end users; the economic situation of local distributors and everyone on earth as replacing kerosene lamps with a product free of any fuel will reduce greenhouse gas emissions and thus reduce climate change. 


\section{References}

[1] Ambade RS, Prabhakar R and Tayade RS (2014), A Review on Gravity Power Generation, Intl. Journal of Innovative Research in Science, Engineering and Technology, 3(4): 11084-11086.

[2] Hasan M, Irfan M and Nadeem A (n.d.), Business Plan of Gravity Light, Bahawalpur: The Islamic University of Bahawalpur.

[3] Riddiford M and Reeves J (2012, December 20), Lighting The Future, Retrieved November 1, 2018, from https://learningfromdogs.com/2012/12/20/lighting-the-future/

[4] Wikimedia Foundation Inc., (n.d.), Gravity. Retrieved November 1, 2018, from https:// en.wikipedia.org/wiki/Gravity 